\title{
Study of Antioxidant Activity of Spinach Extract in Stabilization of Sunflower Oil under Accelerated Storage Conditions
}

\section{Memoona Tehseen ${ }^{1}$, Sajila Hina ${ }^{2 *}$, Alim-un-Nisa ${ }^{2}$ and Naseem Zahra ${ }^{2}$ \\ ${ }^{1}$ Institute of Chemistry, University of the Punjab, Quaid-i-Azam Campus, Lahore, Pakistan; ${ }^{2}$ Food and Biotechnology Research Centre, PCSIR Laboratories Complex, Ferozepur Road, Lahore, Pakistan.}

Abstract | The antioxidant efficacy of the spinach extract was evaluated by addition in sunflower oil (SFO) as natural antioxidant. Three different concentrations of spinach extract, SFO-800, SFO-1600 and SFO$2400 \mathrm{ppm}$ were supplemented to sunflower oil at $25^{\circ} \mathrm{C}$ and $60^{\circ} \mathrm{C}$ along with standard synthetic antioxidants butylated hydroxianisole (BHA), butylated hydroxytoluene (BHT). The stabilization of sunflower oil with spinach extract as natural antioxidant was monitored by evaluating oxidation in terms of peroxide value, free fatty acid value, iodine value, conjugated dienes, conjugated trienes and para-anisidine value. Spinach extract with maximum concentration showed significant effectiveness in oxidative stabilization of the sunflower oil.

Received | June 07, 2018; Accepted | March 07, 2021; Published | May 31, 2021

*Correspondence | Sajila Hina, Food and Biotechnology Research Centre, PCSIR Laboratories Complex, Ferozepur Road, Lahore, Pakistan; Email: sajilahina@gmail.com

Citation | Tehseen, M., S. Hina, A. Nisa and N. Zahra. 2021. Study of antioxidant activity of spinach extract in stabilization of sunflower oil under accelerated storage conditions. Pakistan Journal of Agricultural Research, 34(2): 414-423.

DOI | http://dx.doi.org/10.17582/journal.pjar/2021/34.2.414.423

Keywords | Spinach, Sunflower oil, Oxidation, Stabilization, Natural antioxidant

\section{Introduction}

$\mathrm{R}$ ancidity caused by the oxidation of unsaturated fats is one the major problem in food deterioration and use of antioxidants remained a possible remedy for its prevention (Comert and Gokmen, 2018; Pokorny et al., 2000; Wolf, 2005). Cooking oils are susceptible to rapid degradation resulting in compositional changes and lowered nutritional values at high temperatures during frying (Alzaa et al., 2018; Dutta et al., 2006; Ngassapaa et al., 2012;). These undesirable changes occurring at elevated temperatures are due to oxidation of the fatty acids into free radical species (Dostalova et al., 2005; Dobarganes and Marquez, 2007). Various preservatives and treatments are in common practice such as introducing antioxidants in the oil in order to enhance the shelf-life (Rossell, 2001; Ullah et al., 2003).

Synthetic antioxidants such as butylated hydrox- ianisole (BHA), butylated hydroxytoluene (BHT) and propyl gallate are commonly used in edible oils but their use is discouraged due to their possible ill health effects (Aluyor and Ori-Jesu, 2008; Tortosa et al., 2020). The studies revealed that these synthetic antioxidants are prone to degradation and converted into decomposition products at frying temperatures (Abusaloua et al., 2019). Therefore, their use is prohibited due to toxic and carcinogenic effects. This encourages the demand for using antioxidants of natural origin in order to attain the possible preservation needs and their safety regarding health concerns (Atta et al., 2017; Taghvaei and Jafar, 2015). Natural antioxidants are more benign as compared to artificial antioxidants. There is continuously an increasing research interest in exploration of antioxidants from natural sources such as plants (Bera et al., 2006; Blasi and Cossignani, 2020; Metzner and Poiana, 2018). The enhanced antioxidant activity of plant derived materials has been well proven as they are rich in fla- 
vonoids and polyphenols (Shadyro et al., 2017; Tapera, 2019; Waheed et al., 2018).

Sunflower oil is native to America and was domesticated around 1000 b.c. Major constituents of sunflower seed are oil (38-50\%) and then protein (20\%). Sunflower oil is the major known conventional seed oil due to its increased utility at commercial levels (Skoric, 2009). High quality attributes such as color, aroma, taste and fatty acid profile $(71 \%$ of polyunsaturated fatty acid) makes sunflower oil prominent among other conventional edible oils with 11- 58\% of unsaturated fat (Skoric et al., 2008). Hence there is possibility of increased oxidative deterioration of the sunflower oil because of high polyunsaturation as compared to other edible oils. So the effectiveness of antioxidants in stabilization of sunflower oil will be more pronounced (Kiokias et al., 2009).

The efficacy of several plant based antioxidants were investigated resulting in significant inhibition of lipid peroxidation of sunflower oil (Mariod et al., 2006; Nasirullah and Latha, 2009; Popovich, 2008; Rafiee et al., 2011, 2012; Yim et al., 2011; Zaborowska et al., 2012). The antioxidant potential of the extracts from garlic were studied in sunflower oil stabilization and showed significant results (Iqbal and Bhanger, 2007). Essential oils of citron peel extract addition in sunflower oil to enhance thermal stability was investigated and promising result was obtained (Okhli et al., 2020).

Spinach (Spinacia oleracea) shows exceptionally prominent antioxidant property as it is enriched with plant polyphenols, flavonoids and carotenoid compounds. These phytochemicals play a vital role as radical scavengers and hence exhibiting the anticarcinogenic and health promoting effects (Barzegar et al., 2007; Tehseen et al., 2014).

The objective of present work was to exploit the antioxidant ability of spinach extract in oxidative stabilization of refined sunflower oil at $25^{\circ} \mathrm{C}$ and $60^{\circ} \mathrm{C}$. The usual parameters used as indices of oxidation were assessed to establish the efficacy of spinach extracts as antioxidant in sunflower oil stabilization.

\section{Materials and Methods}

Sample

Refined, Bleached and De-odorized (RBD) sunflower oil were purchased from local market.

\section{Spinach extract}

Spinach extract in methanol was prepared by blending and then antioxidant potential of the extract was scrutinized as reported in our previous work (Tehseen et al., 2014).

\section{Addition in sunflower oil}

The extract was then added in RBD Sunflower oil in three different concentrations (800 ppm, 1600ppm, $2400 \mathrm{ppm}$ ) and thoroughly mixed by vigorous agitation. Synthetic antioxidants BHT and BHA at safe limits of $200 \mathrm{ppm}$ were added in sunflower oils to prepare the standard samples. Samples without any antioxidant were used as control. Both stabilized and control samples $(100 \mathrm{ml})$ were then kept in amber glass bottles at $25^{\circ} \mathrm{C}$ and $60^{\circ} \mathrm{C}$ for 40 days storage. All oil samples were prepared in triplicate and then further assessed for the oxidative deterioration.

\section{Estimation of efficacy of spinach extract}

Different parameters to monitor the oxidation of oil samples were measured for evaluation of efficacy of the added spinach extract in RBD sunflower oil. Peroxide value (POV), Free Fatty Acid Value (FFA), Iodine Value (IV) were measured by standard procedures. Peroxide value is measured in terms of $\mathrm{meq} / \mathrm{Kg}$ of the oil via titrating the liberated iodine using standard sodium thiosulfate solution. FFA and IV were also measured by titrimetric analysis. Conjugated Dienes (CD) and trienes (CT) of the oil samples were analyzed by measuring absorbance at their corresponding wavelength of $232 \mathrm{~nm}$ and $268 \mathrm{~nm}$, respectively. The dilution of sample was made with iso-octane so the absorbance lies in the permissible range of (0.2-0.8 $\lambda$ ) (IUPAC, 1987). The estimation of $p$-Anisidine Value (PAV) was performed spectrophotometrically. Oil samples were dissolved in iso-octane first and then $p$-anisidine reagent added, allowed to react completely until a colored complex formed. Absorbance of the coloured product formed were used for estimation of PAV (Saha et al., 2008).

\section{Statistical study}

Triplicate analysis for each sample was performed and analyzed by one way ANOVA using SPSS ver. 8.0. Mean of each reading was taken as mean $\pm \mathrm{SD}$ showing significant difference of $(\mathrm{P}<0.05)$ (Steel et al., 1997). 


\section{Results and Discussion}

The stability of sunflower oil samples towards oxidative deterioration were analyzed by monitoring the oxidation parameters such as peroxide value (POV), free fatty acid value (FFA), iodine value (IV), conjugated dienes (CD), conjugated trienes (CT), and $p$-anisidine value (PAV) in control (without antioxidant), addition of synthetic antioxidant and with addition of spinach extract in three different concentrations (800 ppm, 1600ppm, 2400ppm) have been studied at $25^{\circ} \mathrm{C}$ and $60^{\circ} \mathrm{C}$ during 40 days storage.

Peroxide value basically indicates the extent of oxidation as a result of formation of peroxides. Initially the POV of sunflower oil (Control) was $0.38 \mathrm{meq} / \mathrm{Kg}$. After 40 days storage the $\mathrm{POVs}$ at $25^{\circ} \mathrm{C}$ and $60^{\circ} \mathrm{C}$ were $19.16 \mathrm{meq} / \mathrm{Kg}$ and $58.0 \mathrm{meq} / \mathrm{Kg}$ respectively (Tables 1 and 2). After the addition of BHA and BHT, the POVs of sunflower oil were reduced which is in accordance with other reported work (Kathy et al., 1994). POVs of sunflower with added spinach extract showed a significant decrease during 40 days storage at $25^{\circ} \mathrm{C}$ and $60^{\circ} \mathrm{C}$. The lowest $\mathrm{POV}$ was observed for the samples with higher concentration of the extracts (Figures 1 and 2). The findings of the study correlate with the previously reported work which showed that the synthetic as well as natural antioxidants were found to reduce the POV of the oils and hence enhancing the stability (Anwar et al., 2003). The enhanced stability of sunflower with added ginger extracts were described (Rehman et al., 2003). Reduction in the POVs of sunflower was observed with methanolic and acetone extracts of rice bran (Chatha et al., 2006). Significant reduction was observed in peroxide values of sunflower oil upon addition of different natural extracts (Anwar et al., 2006). In another study, grape seed extract were utilized to retard the peroxide formation at different heating conditions and there is a marked reduction in POVs (Poiana, 2012). Spinach extract was found to be potent antioxidant and showed a significant reduction in POVs of corn oil (Tehseen et al., 2019). Okhli et al. (2020) reported a decrease in peroxide index with the use of citron peel extracts in sunflower oil.

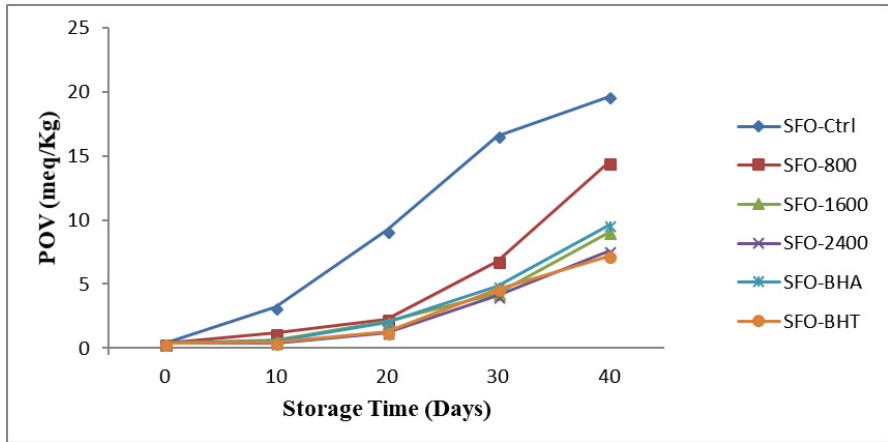

Figure 1: Relative Effect of storage conditions on POV of Sunflower oil at $25^{\circ} \mathrm{C}$.

Table 1: Relative Effect of storage conditions on POV of Sunflower oil at $25^{\circ} \mathrm{C}$.

$\begin{array}{lllllll}\begin{array}{l}\text { Storage } \\ \text { time (Days) }\end{array} & \text { SFO-Ctrl } & \text { SFO-800 } & \text { SFO- } 1600 & \text { SFO-2400 } & \text { SFO-BHA } & \text { SFO-BHT } \\ 0 & 0.38 \pm 0.12 & 0.38 \pm 0.12 & 0.38 \pm 0.12 & 0.38 \pm 0.12 & 0.38 \pm 0.12 & 0.38 \pm 0.12 \\ 10 & 3.20 \pm 0.24 & 1.19 \pm 0.56 & 0.61 \pm 0.93 & 0.41 \pm 0.51 & 0.52 \pm 0.14 & 0.46 \pm 0.31 \\ 20 & 9.18 \pm 0.31 & 2.28 \pm 0.61 & 2.09 \pm 0.26 & 1.22 \pm 0.82 & 1.98 \pm 0.19 & 1.26 \pm 0.66 \\ 30 & 16.56 \pm 0.62 & 6.81 \pm 0.72 & 4.29 \pm 0.34 & 4.08 \pm 0.99 & 4.87 \pm 0.26 & 4.62 \pm 0.73 \\ 40 & 19.61 \pm 0.91 & 14.52 \pm 0.91 & 9.06 \pm 0.46 & 7.61 \pm 0.86 & 9.62 \pm 0.21 & 7.21 \pm 0.52\end{array}$

SFO-Ctrl-Control Sunflower oil without Antioxidant, SFO-BHA-Sunflower oil with BHA SFO-BHT-Sunflower oil with BHT, SFO800- Sunflower with Methanolic spinach extract at 800ppm, SFO-1600-Sunflower with Methanolic spinach extract at 1600ppm, SFO2400-Sunflower with Methanolic spinach extract at 2400ppm.

Table 2: Relative Effect of storage conditions on POV of Sunflower oil at $60^{\circ} \mathrm{C}$.

\begin{tabular}{lllllll}
$\begin{array}{l}\text { Storage } \\
\text { time (Days) }\end{array}$ & SFO-Ctrl & SFO-800 & SFO-1600 & SFO-2400 & SFO-BHA & SFO-BHT \\
0 & $0.38 \pm 0.12$ & $0.38 \pm 0.12$ & $0.38 \pm 0.12$ & $0.38 \pm 0.12$ & $0.38 \pm 0.12$ & $0.38 \pm 0.12$ \\
10 & $9.72 \pm 0.33$ & $6.71 \pm 0.62$ & $5.48 \pm 0.31$ & $4.92 \pm 0.51$ & $5.61 \pm 0.21$ & $4.98 \pm 0.36$ \\
20 & $32.61 \pm 0.51$ & $11.77 \pm 0.59$ & $8.69 \pm 0.16$ & $9.66 \pm 0.31$ & $9.72 \pm 0.63$ & $8.66 \pm 0.48$ \\
30 & $46.37 \pm 0.57$ & $18.57 \pm 0.33$ & $14.89 \pm 0.13$ & $14.26 \pm 0.26$ & $14.22 \pm 0.42$ & $13.92 \pm 0.61$ \\
40 & $58.00 \pm 0.62$ & $28.86 \pm 0.11$ & $20.06 \pm 0.52$ & $19.62 \pm 0.61$ & $19.69 \pm 0.32$ & $17.26 \pm 0.53$ \\
\hline June 2021 & Volume 34 | Issue 2 & Page 416 & & & & Links \\
\end{tabular}


Table 3: Relative Effect of storage conditions on FFA of Sunflower oil at $25^{\circ} \mathrm{C}$.

Storage

time (Days)

0

10

20

30

40

\section{SFO-Ctrl}

$0.108 \pm 0.01$

$0.212 \pm 0.01$

$0.396 \pm 0.03$

$0.501 \pm 0.01$

$0.627 \pm 0.02$
Free fatty acid value FFA-V (\% oleic acid)

SFO -800
$0.108 \pm 0.01$
$0.162 \pm 0.08$
$0.192 \pm 0.09$
$0.262 \pm 0.06$
$0.379 \pm 0.05$

$0.292 \pm 0.04$

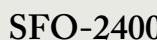

$0.108 \pm 0.01$

$0.128 \pm 0.06$

$0.141 \pm 0.01$

$0.152 \pm 0.04$

$0.184 \pm 0.03$
SFO-BHA

$0.108 \pm 0.01$

$0.132 \pm 0.01$

$0.151 \pm 0.03$

$0.198 \pm 0.02$

$0.283 \pm 0.01$
SFO-BHT

$0.108 \pm 0.01$

$0.120 \pm 0.07$

$0.132 \pm 0.06$

$0.146 \pm 0.03$

$0.169 \pm 0.03$

Table 4: Relative effect of storage conditions on FFA of sunflower oil at $60^{\circ} \mathrm{C}$.

\section{Storage} time (Days)

0

10

20

30

40

\section{SFO-Ctrl}

$0.108 \pm 0.01$

$0.376 \pm 0.04$

$0.723 \pm 0.06$

$0.981 \pm 0.02$

$1.207 \pm 0.03$

Free fatty acid value FFA-V (\% oleic acid)

SFO- 800
$0.108 \pm 0.01$
$0.191 \pm 0.07$
$0.262 \pm 0.09$
$0.356 \pm 0.07$
$0.496 \pm 0.06$

SFO-1600

$0.108 \pm 0.01$

$0.151 \pm 0.05$

$0.208 \pm 0.03$

$0.301 \pm 0.02$

$0.423 \pm 0.04$
SFO-2400

$0.108 \pm 0.01$

$0.133 \pm 0.05$

$0.164 \pm 0.02$

$0.208 \pm 0.05$

$0.241 \pm 0.04$
SFO-BHA

$0.108 \pm 0.01$

$0.146 \pm 0.05$

$0.192 \pm 0.03$

$0.246 \pm 0.01$

$0.392 \pm 0.03$
SFO-BHT

$0.108 \pm 0.01$

$0.123 \pm 0.02$

$0.152 \pm 0.02$

$0.196 \pm 0.05$

$0.222 \pm 0.04$

Table 5: Relative Effect of storage conditions on Iodine Value of Sunflower oil at $25^{\circ} \mathrm{C}$.

\section{Storage}

$\begin{array}{ll}\text { time (Days) } & \text { SFO-Ctrl } \\ 0 & 305 \pm 1.11 \\ 10 & 267 \pm 1.02 \\ 20 & 163 \pm 1.01 \\ 30 & 139 \pm 0.09 \\ 40 & 108 \pm 0.07\end{array}$

Iodine value

$\begin{array}{lllll}\text { SFO-800 } & \text { SFO-1600 } & \text { SFO- } 2400 & \text { SFO-BHA } & \text { SFO-BHT } \\ 305 \pm 1.11 & 305 \pm 1.11 & 305 \pm 1.11 & 305 \pm 1.11 & 305 \pm 1.11 \\ 269 \pm 1.02 & 279 \pm 1.08 & 289 \pm 0.08 & 282 \pm 1.09 & 299 \pm 0.08 \\ 204 \pm 1.06 & 238 \pm 1.06 & 260 \pm 1.02 & 246 \pm 1.14 & 265 \pm 1.02 \\ 189 \pm 1.06 & 201 \pm 1.07 & 238 \pm 1.08 & 213 \pm 1.19 & 246 \pm 1.01 \\ 142 \pm 1.04 & 172 \pm 1.08 & 172 \pm 1.04 & 178 \pm 1.12 & 189 \pm 0.09\end{array}$

Table 6: Relative Effect of storage conditions on Iodine Value of Sunflower oil at $60^{\circ} \mathrm{C}$.

\section{Storage}

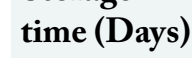

0

10

20

30

40

SFO-Ctrl
$305 \pm 1.11$
$286 \pm 0.09$
$171 \pm 0.07$
$148 \pm 0.06$
$126 \pm 0.08$

SFO-800

$305 \pm 1.11$

$280 \pm 0.09$

$192 \pm 0.06$

$176 \pm 0.07$

$149 \pm 0.09$

Iodine value

Table 7: Relative effect of storage conditions on conjugated dienes value of sunflower oil at $25^{\circ} \mathrm{C}$.

\begin{tabular}{lllllll}
$\begin{array}{l}\text { Storage } \\
\text { time (Days) }\end{array}$ & \multicolumn{2}{l}{ Conjugated dienes value CD $\left(\varepsilon\right.$ at $\left.\boldsymbol{\lambda}_{232}\right)$} \\
0 & SFO-Ctrl & SFO-800 & SFO-1600 & SFO-2400 & SFO-BHA & SFO-BHT \\
0 & $1.72 \pm 0.10$ & $1.72 \pm 0.10$ & $1.72 \pm 0.10$ & $1.72 \pm 0.10$ & $1.72 \pm 0.10$ & $1.72 \pm 0.10$ \\
10 & $6.94 \pm 0.25$ & $5.26 \pm 0.82$ & $4.92 \pm 0.19$ & $4.01 \pm 0.23$ & $4.81 \pm 0.19$ & $4.08 \pm 0.19$ \\
20 & $12.04 \pm 0.22$ & $8.06 \pm 0.96$ & $6.89 \pm 0.26$ & $6.04 \pm 0.25$ & $6.72 \pm 0.21$ & $6.22 \pm 0.17$ \\
30 & $16.42 \pm 0.48$ & $11.23 \pm 0.77$ & $8.21 \pm 0.31$ & $7.21 \pm 0.19$ & $8.06 \pm 0.23$ & $7.43 \pm 0.21$ \\
40 & $18.23 \pm 0.27$ & $12.92 \pm 0.80$ & $8.96 \pm 0.18$ & $7.89 \pm 0.15$ & $8.79 \pm 0.18$ & $7.99 \pm 0.27$
\end{tabular}

Free fatty acid is uncombined fatty acids present in fats or oils. The increase of FFA value indicates the lipid peroxidation. FFA value of RBD sunflower oil was determined at $25^{\circ} \mathrm{C}$ and $60^{\circ} \mathrm{C}$ for 40 days storage. The 
FFA value of sunflower oil without any antioxidant (control) was more pronounced at $60^{\circ} \mathrm{C}$. However, samples with BHA and BHT showed less FFA values. Similarly, methanolic spinach extract at three different concentration levels also showed reduction in FFA value. (Tables 3 and 4; Figures 3 and 4) Iodine value depicts the availability of unsaturated fatty acids in oils and fat. Oils with more unsaturation are more prone to oxidation (Azeez and Ejeta, 2013). The changes in the IVs of the sunflower oil with added synthetic antioxidant BHA and BHT and spinach extract showed the significant reduction as compared to control. (Tables 5 and 6) IVs of samples with spinach extract showed prominent effect with an increase in IVs during 40 days storage at $25^{\circ} \mathrm{C}$ and $60^{\circ} \mathrm{C}$ (Figures 5 and 6). Abd-El-Ghany et al. (2010) examined the FFA and IVs of the sunflower oil supplemented with olive waste cake extracts and claimed the efficacy of extracts in retarding the oxidative deterioration. FFA and IVs of different blend oil samples were also studied showing significant effect of leaf extracts of Eucalyptus citriodora in preventing oxidation (Ali et al., 2016).

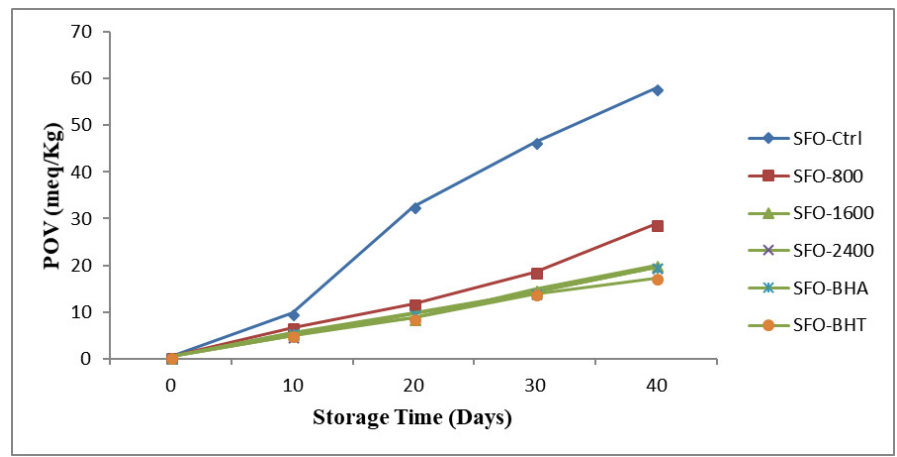

Figure 2: Relative Effect of storage conditions on POV of Sunflower oil at $60^{\circ} \mathrm{C}$.

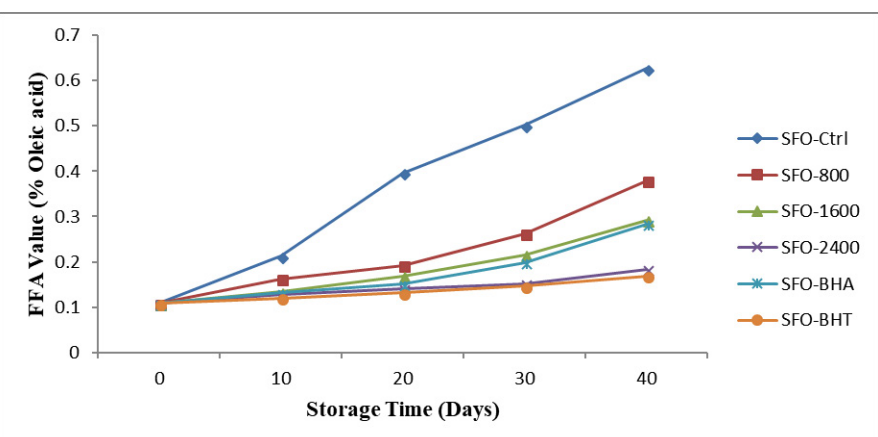

Figure 3: Relative Effect of storage conditions on FFA of Sunflower oil at $25^{\circ} \mathrm{C}$.

Conjugated dienes (CD) and conjugated trienes (CT) are also predictive of extent of oxidation. Increase in the CD (Tables 7 and 8; Figures 7 and 8) and CT (Tables 9 and 10; Figures 9 and 10) values is observed for control whereas with the addition of antioxidants (Erkan et al., 2009) and spinach extract a significant reduction was observed showing optimum results with SFO-2400. Poiana (2012) also analyzed CD and CT values of sunflower oil stabilized with grape seed extract and results showed significant inhibition of $\mathrm{CD}$ and $\mathrm{CT}$ values. Oils having low values of $\mathrm{CD}$ and $\mathrm{CT}$ are rather more stable towards oxidation (Chatha et al., 2006). The use of garlic extract for inhibiting the lipid peroxidation in sunflower oil was reported. Garlic extract showed significant reduction in CD and CT values (Iqbal and Bhangar, 2007). Anwar et al. (2006) reported the retardation in the CD and CT values of sunflower oil supplemented with different natural extracts at varying temperatures. Moringa oleifera leave extracts were used in sunflower and showed significant inhibition of oxidation (Siddiq et al., 2005). Similar results were obtained when spinach extract was used in stabilization of corn oil showing significant decrease in CD and CT values (Tehseen et al., 2019).

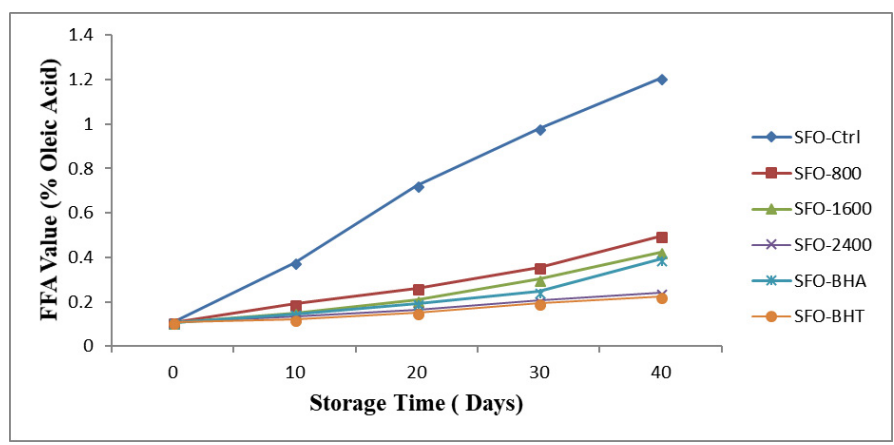

Figure 4: Relative Effect of storage conditions on FFA of Sunflower oil at $60^{\circ} \mathrm{C}$.

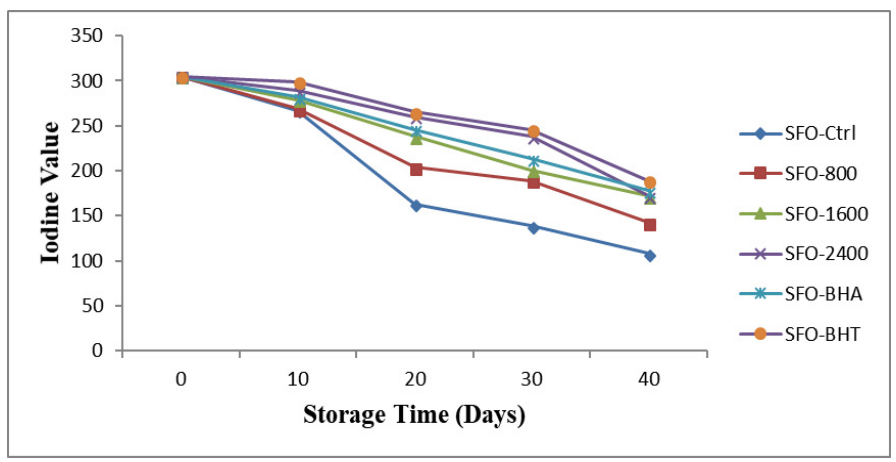

Figure 5: Relative Effect of storage conditions on Iodine Value of Sunflower oil at $25^{\circ} \mathrm{C}$.

$p$-Anisidine value (PAV) depicts the extent of formation of aldehydes and ketones as degradation products of unsaturated fats. Addition of synthetic antioxidants and spinach extract prominently decrease the PAVs of the sunflower oil as compared to control. Spinach extract with a maximum concentration 
2400ppm significantly retard the carbonyl moieties formation as compared to control (Tables 11 and 12; Figures 11 and 12). The findings correlates with the previously reported work which explained the efficacy of spinach extract in corn oil oxiditave stabilization (Tehseen et al., 2019). Various studies acclaimed $p$-anisidine value to monitor the oxidative deterioration of sunflower oil supplemented with different antioxidants of natural origin such as citron peel extract (Okhli et al., 2020), grape seed extract (Poiana, 2012), rice bran extract (Chatha et al., 2006), roselle seed extracts (Nyam et al., 2012). All studies sufficiently describes the effectiveness of natural plant extracts in retarding the PAVs.

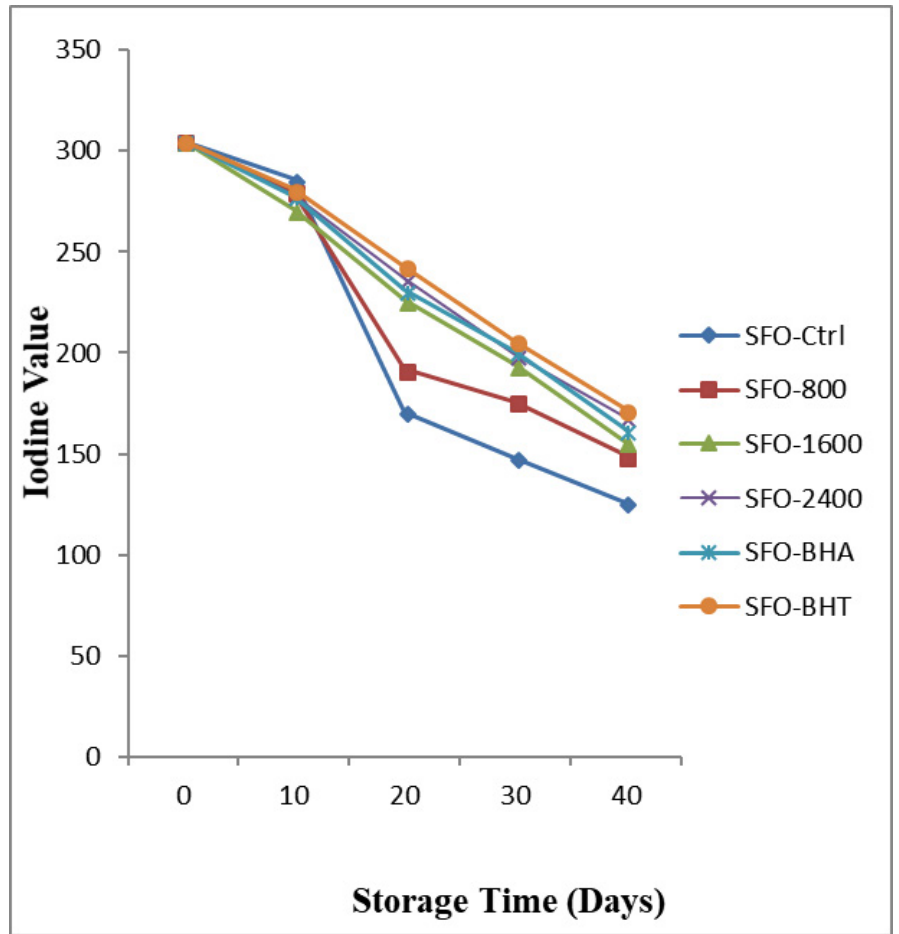

Figure 6: Relative Effect of storage conditions on Iodine Value of Sunflower oil at $60^{\circ} \mathrm{C}$.

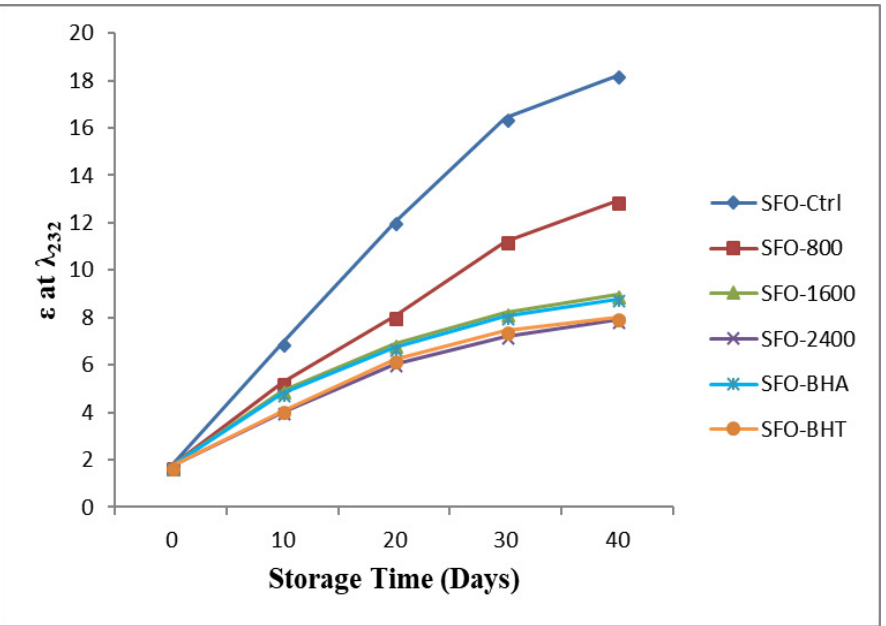

Figure 7: Relative Effect of storage conditions on Conjugated Dienes Value of Sunflower oil at $25^{\circ} \mathrm{C}$.

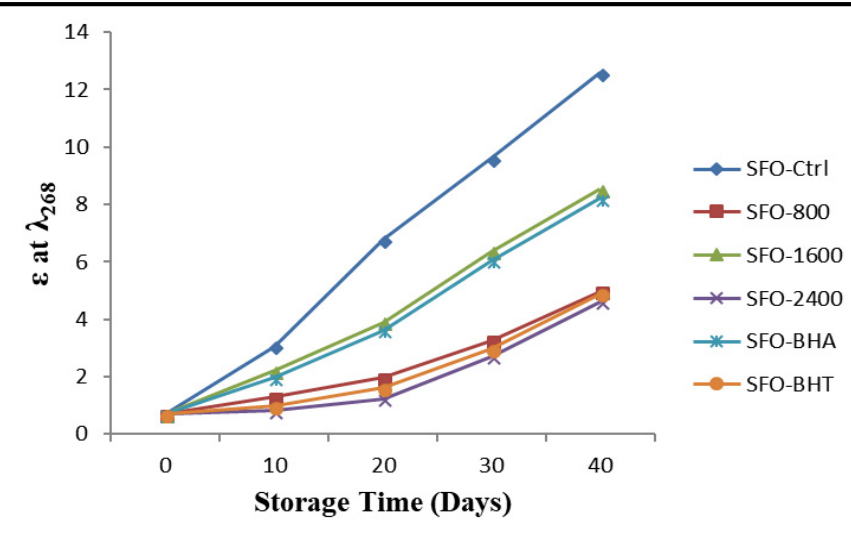

Figure 8: Relative Effect of storage conditions on Conjugated Dienes Value of Sunflower oil at $60^{\circ} \mathrm{C}$.

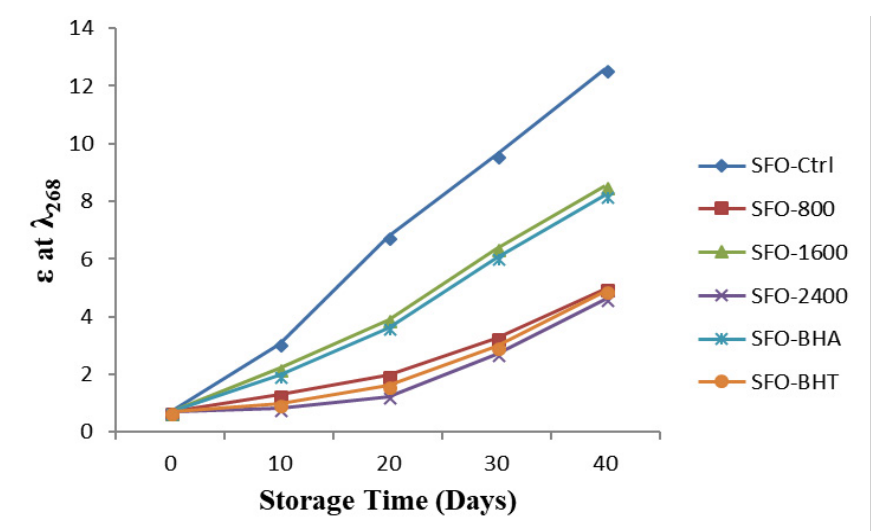

Figure 9: Relative Effect of storage conditions on Conjugated Trienes Value of Sunflower oil at $25^{\circ} \mathrm{C}$.
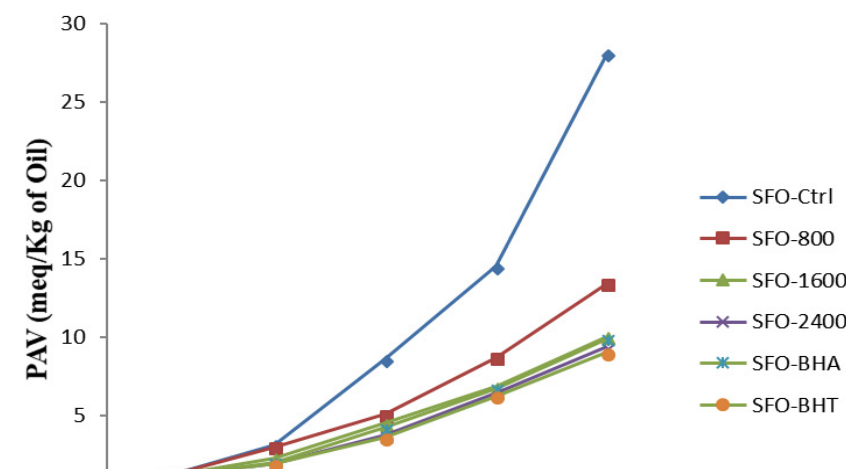

Figure 10: Relative Effect of storage conditions on Conjugated Trienes Value of Sunflower oil at $60^{\circ} \mathrm{C}$.

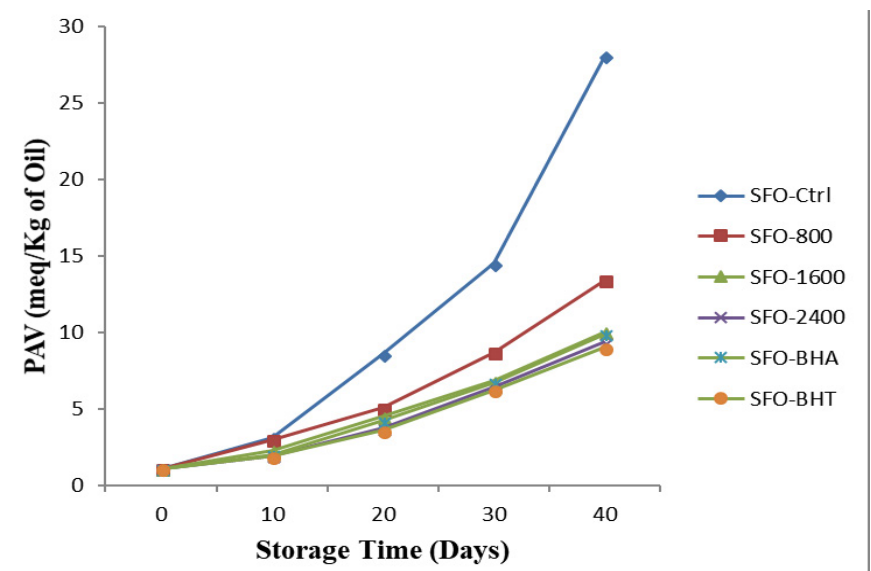

Figure 11: Relative Effect of storage conditions on Para Anisidine Value PV of Sunflower oil at $25^{\circ} \mathrm{C}$. 
Table 8: Relative effect of storage conditions on conjugated dienes value of sunflower oil at $60^{\circ} \mathrm{C}$.

\section{Storage} time (Days)

0

10

20

30

40

\section{SFO-Ctrl}

$1.72 \pm 0.10$

$8.78 \pm 0.17$

$16.72 \pm 0.29$

$18.23 \pm 0.31$

$20.58 \pm 0.18$
SFO-800

$1.72 \pm 0.10$

$6.82 \pm 0.13$

$8.91 \pm 0.16$

$11.83 \pm 0.19$

$13.06 \pm 0.16$
Conjugated dienes value $\mathrm{CD}\left(\varepsilon\right.$ at $\left.\lambda_{232}\right)$

$\begin{array}{llll}\text { SFO-1600 } & \text { SFO- } 2400 & \text { SFO-BHA } & \text { SFO-BHT } \\ 1.72 \pm 0.10 & 1.72 \pm 0.10 & 1.72 \pm 0.10 & 1.72 \pm 0.10 \\ 5.22 \pm 0.26 & 4.29 \pm 0.42 & 5.01 \pm 0.70 & 4.63 \pm 0.21 \\ 7.46 \pm 0.19 & 6.56 \pm 0.51 & 7.26 \pm 0.61 & 6.89 \pm 0.32 \\ 8.99 \pm 0.27 & 7.82 \pm 0.48 & 8.86 \pm 0.69 & 8.01 \pm 0.29 \\ 9.81 \pm 0.21 & 8.91 \pm 0.14 & 9.92 \pm 0.59 & 9.06 \pm 0.16\end{array}$

Table 9: Relative effect of storage conditions on conjugated trienes value of sunflower oil at $25^{\circ} \mathrm{C}$.

\section{Storage} time (Days)

0

10

20

30

40

\section{SFO-Ctrl}

$0.69 \pm 0.27$

$3.07 \pm 0.26$

$6.78 \pm 0.31$

$9.61 \pm 0.29$

$12.59 \pm 0.23$

Conjugated trienes value CT ( $\varepsilon$ at $\left.\lambda_{268}\right)$

$\begin{array}{lllll}\text { SFO- } 800 & \text { SFO }-1600 & \text { SFO }-2400 & \text { SFO-BHA } & \text { SFO-BHT } \\ 0.69 \pm 0.27 & 0.69 \pm 0.27 & 0.69 \pm 0.27 & 0.69 \pm 0.27 & 0.69 \pm 0.27 \\ 1.29 \pm 0.21 & 2.21 \pm 0.46 & 0.82 \pm 0.21 & 1.98 \pm 0.41 & 0.98 \pm 0.21 \\ 1.98 \pm 0.96 & 3.89 \pm 0.38 & 1.24 \pm 0.16 & 3.62 \pm 0.39 & 1.62 \pm 0.35 \\ 3.26 \pm 0.77 & 6.37 \pm 0.41 & 2.71 \pm 0.21 & 6.05 \pm 0.35 & 2.96 \pm 0.36 \\ 4.98 \pm 0.80 & 8.52 \pm 0.43 & 4.62 \pm 0.19 & 8.21 \pm 0.38 & 4.89 \pm 0.32\end{array}$

Table 10: Relative effect of storage conditions on conjugated trienes value of sunflower oil at $60^{\circ} \mathrm{C}$.

\section{Storage} time (Days)

0

10

20

30

40
SFO-Ctrl

$0.69 \pm 0.27$

$3.91 \pm 0.13$

$7.65 \pm 0.19$

$10.24 \pm 0.21$

$13.56 \pm 0.18$

\section{Conjugated trienes value CT $\left(\varepsilon\right.$ at $\left.\lambda_{268}\right)$}

SFO-800

$0.69 \pm 0.27$

$1.36 \pm 0.22$

$2.12 \pm 0.26$

$3.99 \pm 0.27$

$5.96 \pm 0.22$

SFO-1600

SFO-2400

SFO-BHA

$0.69 \pm 0.27$

$2.46 \pm 0.42$

$4.92 \pm 0.39$

$7.43 \pm 0.43$

$8.91 \pm 0.38$
$0.69 \pm 0.27$

$0.99 \pm 0.20$

$1.68 \pm 0.23$

$3.62 \pm 0.25$

$5.57 \pm 0.19$
$0.69 \pm 0.27$

$1.99 \pm 0.36$

$4.67 \pm 0.42$

$6.96 \pm 0.40$

$8.52 \pm 0.37$
SFO-BHT

$0.69 \pm 0.27$

$1.01 \pm 0.45$

$1.82 \pm 0.39$

$3.79 \pm 0.37$

$5.72 \pm 0.42$

Table 11: Relative Effect of storage conditions on Para Anisidine Value PV of Sunflower oil at $25^{\circ} \mathrm{C}$.

\section{Storage}

time (Days)

0

10

20

30

40
SFO-Ctrl

$1.08 \pm 0.03$

$3.12 \pm 0.30$

$8.61 \pm 0.32$

$14.52 \pm 0.26$

$28.10 \pm 0.21$

SFO- 800
$1.08 \pm 0.03$
$3.01 \pm 0.07$
$5.09 \pm 0.09$
$8.72 \pm 0.05$
$13.43 \pm 0.12$

Para anisidine value $\mathrm{PV}(\mathrm{meq} / \mathrm{Kg})$

$\begin{array}{llll}\text { SFO-1600 } & \text { SFO }-2400 & \text { SFO-BHA } & \text { SFO-BHT } \\ 1.08 \pm 0.03 & 1.08 \pm 0.03 & 1.08 \pm 0.03 & 1.08 \pm 0.03 \\ 2.28 \pm 0.07 & 1.94 \pm 0.08 & 2.01 \pm 0.13 & 1.92 \pm 0.06 \\ 4.52 \pm 0.05 & 3.72 \pm 0.06 & 4.22 \pm 0.09 & 3.61 \pm 1.03 \\ 6.82 \pm 0.04 & 6.46 \pm 0.06 & 6.73 \pm 0.08 & 6.23 \pm 0.07 \\ 10.03 \pm 0.06 & 9.38 \pm 0.09 & 9.91 \pm 0.12 & 9.03 \pm 0.02\end{array}$

Table 12: Relative effect of storage conditions on para anisidine value $\mathrm{PV}$ of sunflower oil at $60^{\circ} \mathrm{C}$.

\section{Storage} time (Days)

0

10

20

30

40

SFO-Ctrl
$1.08 \pm 0.03$
$5.79 \pm 0.19$
$15.06 \pm 0.16$
$26.39 \pm 0.16$
$37.27 \pm 0.18$

\section{Para anisidine value $\mathrm{PV}(\mathrm{meq} / \mathrm{Kg})$}

$\begin{array}{llll}\text { SFO-1600 } & \text { SFO- } 2400 & \text { SFO-BHA } & \text { SFO-BHT } \\ 1.08 \pm 0.03 & 1.08 \pm 0.03 & 1.08 \pm 0.03 & 1.08 \pm 0.03 \\ 4.02 \pm 0.17 & 3.81 \pm 0.07 & 3.98 \pm 0.06 & 3.25 \pm 0.05 \\ 8.12 \pm 0.12 & 7.69 \pm 1.02 & 7.91 \pm 0.02 & 7.62 \pm 0.04 \\ 13.61 \pm 0.09 & 12.38 \pm 0.08 & 13.37 \pm 0.04 & 11.31 \pm 0.07 \\ 18.86 \pm 0.11 & 17.29 \pm 0.08 & 18.69 \pm 0.04 & 16.52 \pm 0.04\end{array}$




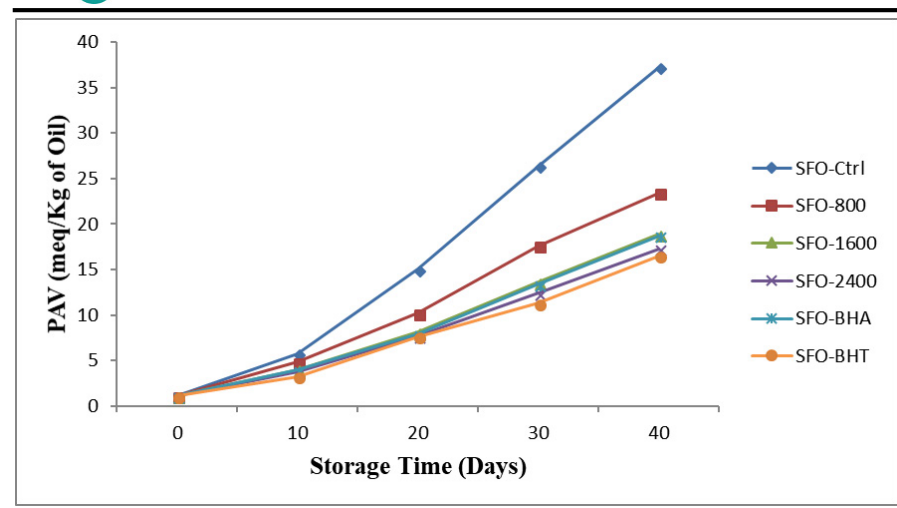

Figure 12: Relative Effect of storage conditions on Para Anisidine Value PV of Sunflower oil at $60^{\circ} \mathrm{C}$

\section{Conclusions and Recommendations}

The current research showed the efficacy of spinach extract for enhancing the sunflower oil stability even at $60^{\circ} \mathrm{C}$ and supplementation with spinach extract was dose-dependent. Maximum retardation in the oxidative deterioration of sunflower oil was observed with the maximum concentration of added spinach extract. Spinach extracts with high antioxidant profile are helpful during oil storage. The results encourage the use of natural antioxidants in commonly used vegetable oils to enhance the oxidative stability.

\section{Novelty Statement}

To the best of our knowledge this study is novel and first study conducted on use of spinach extract as natural antioxidant in oxidative stabilization of sunflower oil.

\section{Author's Contribution}

Memoona Tehseen: Conceived the idea and performed experimental work.

Sajila Hina: Data analysis and wrote Manuscript. Alim-un-Nisa: Provided technical input at every step.

Naseem Zahra: Overall management of the article.

\section{Conflict of interest}

The authors have declared no conflict of interest.

\section{References}

Abd-El-Ghany, M.E., M.S. Ammar and A.E. Hegazy. 2010. Use of olive waste cake extract as a natural antioxidant for improving the stability of heated sunflower oil. World Appl. Sci. J.,

\section{1(1): 106-113.}

Abusaloua,A., G.Mohamed,A.Ali and W.Zahmol. 2019. Food additives and preservatives as slow poisons. J. Appl. Sci., 2(3): 42-48. https://doi. org/10.47891/sabujas.v2i3.42-48

Ali, S., S.A.S. Chatha, Q. Ali, A.I. Hussain, S.M. Hussain and R. Perveen. 2016. Oxidative stability of cooking oil blend stabilized with leaf extract of Eucalyptus citriodora. Int. J. Food. Prop. 19: 1556-1565. https://doi.org/10 $.1080 / 10942912.2015 .1047514$

Aluyor, E.O. and M. Ori-Jesu. 2008. The use of antioxidants in vegetable oils. A review. Afr. J. Biotech. Acad. J., 7(25): 4836-4842.

Alzaa, D.F., C. Guillaume and L. Ravetti. 2018. Evaluation of chemical and physical changes in different commercial oils during heating. Acta Sci. Nutr. Health, 2(6): 02-11.

Anwar, F., A. Jamil, S. Iqbal and M.A. Sheikh. 2006. Antioxidant activity of various plant extracts under ambient and accelerated storage of sunflower oil. Grassay. Y. Aceites. 57(2): 189197. https://doi.org/10.3989/gya.2006.v57. i2.36

Anwar, F., M.I., Bhanger and S. Yasmeen. 2003. Antioxidant activity of some natural extracts in corn oil. In: N. Murata, M.Yamada, I. Nishida, H. Okuyama, J. Sekiya, and W. Hajime (Eds.), Advaned research of plant lipid, Netherlands: Kluwer Publishers. pp. 24-27. https://doi. org/10.1007/978-94-017-0159-4_5

Atta, E.M., N.H. Mohamed and A.A.M. Abdelgawad. 2017. Antioxidants: an overview on the natural and synthetic types. Eur. Chem. Bull., 6(8): 365-375. https://doi.org/10.17628/ ecb.2017.6.374-384

Azeez, T.O. and O.K. Ejeta. 2013. Effects of antioxidants on the oxidative stability of vegetable oil at elevated temperature. Int. J. Appl. Sci. Tech., 3(5): 107-115.

Barzegar, M., F. Erfani, A. Jabbari and M.R. Hassandokht. 2007. Chemical composition of 15 spinach (Spinacea oleracea L.) cultivars grown in Iran. Ital. J. Food Sci., 19: 309-318.

Bera, D., D. Lahiri and A. Nag. 2006. Studies on a natural antioxidant for stabilization of edible oil and comparison with synthetic antioxidants. J. Food Eng., 74: 542-545. https://doi. org/10.1016/j.jfoodeng.2005.03.042

Blasi, F. and L. Cossignani. 2020. An overview of natural extracts with antioxidant activity for the 
improvement of the oxidative stability and shelf life of edible oils. Processes, 8(8): 956. https:// doi.org/10.3390/pr8080956

Chatha, S.A.S., F. Anwar, M. Manzoor and J.R. Bajwa. 2006. Evaluation of the antioxidant activity of rice bran extracts using different antioxidant assays. Grasas. Y. Aceites., 57: 328335. https://doi.org/10.3989/gya.2006.v57. i3.56

Comert, E.D. and V. Gokmen. 2018. Evolution of food antioxidants as a core topic of food science for a century. Food Res.Int., 105: 76-93. https:// doi.org/10.1016/j.foodres.2017.10.056

Dobarganes, M.C. and G. Marquez-Ruiz. 2007. Formation and analysis of oxidized monomeric, dimeric and higher oligomeric triglycerides. In: M.D. Erickson (ed.) Deep Frying; Chemistry, Nutrition and Practical Applications. AOCS Press, Urbana, IL. pp. 87-110. https://doi. org/10.1016/B978-1-893997-92-9.50012-8

Dostalova, J., P. Hanzlik, Z. Reblova and J. Pokorny. 2005. Oxidative changes of vegetable oils during microwave heating. Czech J. Food Sci., 23: 230-239. https://doi.org/10.17221/3396CJFS

Dutta, P.C., R. Przybylski, M.N.A. Eskin and L.A. Appelqvist. 2006. Formation, analysis and health effects of oxidized sterols in frying fat. In: M.D. Erickson (ed.) Deep Frying; Chemistry, Nutrition and Practical Applications. AOCS Press, Urbana, IL. pp. 111-164. https://doi. org/10.1016/B978-1-893997-92-9.50013-X

Erkan, N., G. Ayranci, G. and E. Ayranci. 2009. A kinetic study of oxidation development in sunflower oil under microwave heating: effect of natural antioxidants. Food Res. Int., 42: 1171-1177. https://doi.org/10.1016/j. foodres.2009.06.003

International Union of Pure and Applied Chemistry (IUPAC). 1987. Standard methods for the analysis of oils, Fats and Derivatives, $7^{\text {th }}$ Rev. Edited by C. Paquot and A. Hautfenne, Blackwell Scientific London.

Iqbal, S. and M.I. Bhanger. 2007. Stabilization of sunflower oil by garlic extract during accelerated storage. Food Chem., 100: 246-254. https:// doi.org/10.1016/j.foodchem.2005.09.049

Kathy, G., B. Randel, T. Peter and C.F. George. 1994. Effect of three different preservatives systems on the stability of extended dog food subjected to ambient and high temperature storage. J. Nutr., 124: 26385-26425.

Kiokias, S., C. Dimakou and V. Oreopoulou. 2009. Activity of natural carotenoid preparations against the autoxidative deterioration of sunflower oil-in-water emulsions. Food Chem., 114: 1278-1284. https://doi. org/10.1016/i.foodchem.2008.10.087

Mariod, A., B. Matthaus and I. Hussein. 2006. Antioxidant activities of extracts from Combretum hartmannianum and Guiera senegalensis on the oxidative stability of sunflower oil. Emirates J. Food Agric., 17: 2028. https://doi.org/10.9755/ejfa.v12i1.5136

Metzner, C. and M. Poiana. 2018. Fruit-based natural antioxidants in edible oils: A review. J. Agroaliment. Proc. Technol., 24(2): 110-117.

Nasirullah and R.B. Latha. 2009. Storage stability of sunflower oil with added natural antioxidant concentrate from sesame seed oil. J. Oleo Sci., 58(9): 453-459. https://doi.org/10.5650/ jos. 58.453

Ngassapaa,F.,S.Nyandoroa and T.Mwaisakab.2012. Effects of temperature on the physicochemical properties of traditionally processed vegetable oils and their blends. Tanzania J. Sci., 38(3): 1-11.

Nyam, K.L., Y.N. The, C.P. Tan and L. Kamariah. 2012. In vitro antioxidant activities of extract and oil from roselle (Hibiscus sabdariffa L.) seed against sunflower oil autoxidation. Malaysian J. Nut., 18(2): 265-274.

Okhli, S., H. Mirzaei and S.E. Hosseini. 2020. Antioxidant activity of citron peel (Citrus medica L.) essential oil and extract on stabilization of sunflower oil. Oilseeds, Fats, Crops and Lipids. 27: 1-7. https://doi.org/10.1051/oc1/2020022

Poiana,M.A.,2012.Enhancing oxidative stability of sunflower oil during convective and microwave heating using grape seed extract. Int. J. Mol. Sci., 13: 9240-9259. https://doi.org/10.3390/ ijms13079240

Pokorny, J., N. Yanishlieva and M. Gordon. 2000. Antioxidants in food practical applications. CRC press, New York. https://doi. org/10.1201/9781439823057

Popovich, K.M., 2008. The influence of natural antioxidants on the oxidative stability of iodinefortified sunflower oil in the process of storage. Surf. Eng. Appl. Electrochem., 44(5): 415-421 https://doi.org/10.3103/S106837550805013X. Rafiee, Z., S.M. Jafari, M. Alami and M. Khomeiri. 
2011. Antioxidant properties of olive leaf extract and its application in sunflower oil. J. Food Sci. Res., 21: 12-24.

Rafiee, Z., S.M. Jafari, M. Alami and M. Khomeiri. 2012. Antioxidant effect of microwave-assisted extracts of olive leaves on sunflower oil. J. Agri. Sci. Tech., 14: 1497-1509.

Rehman, Z., A.M. Salariya and F. Habib. 2003. Antioxidant activity of ginger extract in sunflower oil. J. Sci. Food Agric., 83: 624-629. https://doi.org/10.1002/jsfa.1318

Rossell, J.B., 2001. Factors affecting the quality of frying oils and fats. In: J.B. Rossell (ed.) Frying Improving Quality. Woodhead Publishing, Cambridge. pp. 115-164. https:// doi.org/10.1533/9781855736429.2.115

Saha, M.R., M.A. Alam, R. Akter and R. Jahangir. 2008. In vitro free radical scavenging activity of Ixora coccinea L. Bangladesh J. Pharm., 3: 90-96. https://doi.org/10.3329/bjp.v3i2.838

Shadyro, O.I., A.A. Sosnovskaya and I.P. Edimecheva. 2017. Flaxseed oil stabilization using natural and synthetic antioxidants. Eur. J. Lipid Sci. Tech., 119(10): 1700079. https://doi. org/10.1002/ejlt.201700079

Siddiq, A., F. Anwar, M. Manzoor and M. Fatima. 2005. Antioxidant activity of different solvent extracts of Moringa oleifera leaves under accelerated storage conditions of sunflower oil. Asian J. Plant Sci., 4(6): 630-635. https://doi. org/10.3923/ajps.2005.630.635

Skoric, D., 2009. Possible uses of sunflower in proper human nutrition. Med. Pregl., 62: 105110.

Skoric, D., S. Jocic, Z. Sakac and N. Lecic. 2008. Genetic possibilities for altering sunflower oil quality to obtain novel oils. Canadian J. Physiol. Pharmacol., 86(4): 215-221. https:// doi.org/10.1139/Y08-008

Steel, R.G.D., J.H. Torrie and D.A. Dicky. 1997. Principles and procedures of statistics: A biometrical approach. $3^{\text {rd }}$ edn. McGraw Hill Book Co. Inc., New York.

Taghvaei, M. and M.S. Jafar. 2015. Application and stability of natural antioxidants in edible oils in order to substitute synthetic additives. J. Food Sci. Tech., 52(3): 1272-1282. https://doi. org/10.1007/s13197-013-1080-1

Tapera, M., 2019. Towards greener preservation of edible oils: A mini-review. Asian J. Appl. Chem. Res., 4(1): 1-8. https://doi.org/10.9734/ ajacr/2019/v4i1-230105

Tehseen, M., S. Hina, A. Nisa and A. Ahmad. 2014. Antioxidant potential of differently irrigated soil grown varieties of spinach. World App. Sci. J., 32(7): 1235-1241.

Tehseen, M., S. Hina, A. Nisa and A. Ahmad. 2019. Oxidative stabilization of corn oil with spinach extract. Bangladesh.J. Sci. Ind. Res., 54(4): 375382. https://doi.org/10.3329/bjsir.v54i4.44572

Tortosa, V., V. Pietropaolo, V. Brandi, G. Macari, A. Pasquadibisceglie and F. Polticelli. 2020. Computational methods for the identification of molecular targets of toxic food additives. Butylated Hydroxytoluene as a case study. Molecules, 25(9): 2229. https://doi. org/10.3390/molecules25092229

Ullah, J., M. Hamayoun, T. Ahmad, M. Ayub and M. Zarafullah. 2003. Effect of light, natural and synthetic antioxidants on stability of edible oil and fats. Asian J. Plant Sci., 2(1724): 1192-1194. https://doi.org/10.3923/ ajps.2003.1192.1194

Waheed, S., A. Hasnain and A. Ahmad. 2018. Evaluating the potential of botanical extracts and fractions as substitutes of chemical antioxidants in edible oils. Pak. J. Bot., 50(5): 1999-2004.

Wolf, G., 2005. The discovery of the antioxidant function of vitamin $\mathrm{E}$ : the contribution of Henry A. Mattill. J. Nut., 135(3): 363-366. https://doi.org/10.1093/jn/135.3.363

Yim, H.S., F.Y. Chye, P.Y. Heng and C.W. Ho. 2011. Oxidative stability of sunflower oil supplemented with medicinal split gill mushroom, Schizophyllum commune Fr.:Fr. extract during accelerated storage. Int. J. Med. Mushrooms, 13(4): 357-368. https://doi. org/10.1615/IntJMedMushr.v13.i4.60

Zaborowska, Z., K. Przygonski and A. Bilska. 2012. Antioxidative effect of thyme (Thymus vulgaris) in sunflower oil. Acta Sci. Pol. Technol. Aliment., 11(3): 283-291. 